\title{
RANCANGAN VIRTUAL ACCOUNT SEBAGAI MEDIA PEMBAYARAN PADA PERGURUAN TINGGI RAHARJA
}

\author{
Tuti Nurhaeni ${ }^{1}$ \\ Khanna Tiara $^{2}$ \\ Dwiki Fahliandhini ${ }^{3}$ \\ Jl. Jendral Sudirman No. 40, Modernland, Tangerang

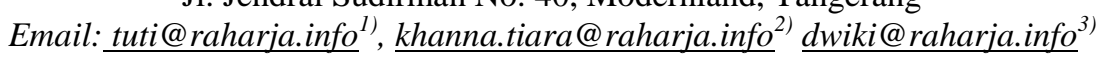

\begin{abstract}
ABSTRAK
Di dalam suatu perkuliahan media pembayaran merupakan salah satu hal penting karena media pembayaran digunakan untuk membayar kebutuhan kampus agar dapat memberikan fasilitas terbaik untuk mahasiswa. Metode pembayaran yang diterapkan harus memudahkan mahasiswa untuk melakukannya.Media pembayaran yang digunakan biasanya secara tunai, transfer, dan sebagainya. Untuk saat ini metode pembayaran masih secara manual yaitu menggunakan nomor rekening bank dan harus mengantri dikasir ketika ingin melakukan pembayaran. Untuk meningkatkan kebutuhan mahasiswa maka dibuatlah pembayaran kuliah secara online agar lebih mudah dan aman yaitu dengan menggunakan Virtual Account. Pada penelitian menggunakan metode mind mapping dan analisa SWOT. Virtual Account (VA) adalah nomor rekening virtual yang disediakan oleh bank untuk setiap mahasiswa Perguruan Tinggi Raharja. Dengan VA, setiap mahasiswa memiliki nomor rekening pribadi yang digunakan sebagai rekening tujuan pada saat melakukan pembayaran uang kuliah. Nomor VA bersifat unik sehingga nomor VA seorang mahasiswa tidak mungkin sama dengan nomor VA mahasiswa lainnya. Dengan adanya VA maka kemudahan pengenalan pembayaran mahasiswa pada bagian keuangan Perguruan Tinggi Raharja. Pada saat melakukan pembayaran mahasiswa tidak perlu lagi menulis nama atau NIM pada catatan bank, karena setiap nomor VA sudah melekat pada NIM tersebut. Dengan demikian mahasiswa terhindar dari kesalahan penulisan pada kolom catatan bank. Mahasiswa juga dapat melakukan pembayaran selain melalui setor tunai, pembayaran juga bisa dilakukan melalui kanal-kanal lainnya seperti ATM, Mobile atau SMS Banking dan Internet Banking sesuai dengan layanan yang tersedia pada Bank yang bersangkutan. Penyediaaan Virtual Account diharapkan bisa memberikan kemudahan bagi setiap mahasiswa Perguruan Tinggi Raharja dalam melakukan pembayaran uang kuliahnya. Di sisi lain, pihak Perguruan Tinggi Raharja juga akan lebih mudah mengenali pembayaran uang kuliah setiap mahasiswanya.
\end{abstract}

Kata kunci : Nomor Rekening, Pembayaran, Virtual Account

\section{ABSTRACT}

In a lecture on media payments is one of the most important things because the media payment used to pay for the needs of the campus in order to provide the best facilities for students. The payment method that is applied should make it easier for students to do so. Payment media used usually in cash, transfer, and so on. The student then needs to increase the payment was made lectures online for easy and safe by using a Virtual Account. On research method using mind mapping and SWOT analysis. Virtual accounts (VA) is a virtual account number provided by the

Vol.2 No.2 - Agustus 2016 
bank for any College student Raharja. With the VA, every student has a personal account numbers that are used as account destination upon payment of tuition fees. The number of VA is unique so the number of VA a student didn't may be equal to the number of other students of the VA. With the VA then ease the introduction of payment on the part of student finance College Raharja. At the time of payment the student no longer need to write a name or NIM on bank notes, as any number of VA is already attached to the NIM. Thus students avoid writing errors in a column of bank notes. Students can also make payments other than through cash payments, setor can also be done through other canals such as ATMs, Mobile or SMS Banking and Internet Banking in accordance with the services available on the Bank in question. Penyediaaan Virtual accounts are expected to be able to provide ease for every College student Raharja in payment of money to attend. On the other hand, the College Raharja would also more easily recognize the payment of tuition per student.

Keywords : Account number, Payment, Virtual Account

\section{PENDAHULUAN}

Seiring tumbuh dan berkembangnya Perguruan Tinggi Raharja dalam meningkatkan aktivitas, kemajuan ini telah mendorong bagian keuangan untuk berusaha mengatasi segala permasalahan yang ada sehingga menuntut kemampuan dan kecakapan di bagian keuangan dalam memberikan pelayanan keuangan kepada mahasiswa. Sehingga diharapkan mampu mengatasi masalah yang terjadi. Pembayaran merupakan berpindahnya hak pemilikan atas sejumlah uang atau dan dari pembayar kepada penerimanya, baik langsung ataupun melalui media jasa-jasa perbankan ${ }^{\text {([Hasibuan }}$ 2001])

Perguruan Tinggi Raharja membutuhkan suatu sistem pembayaran yang mudah digunakan dalam melakukan transaksi pembayaran, untuk itu dapat digunakan sebuah sistem pembayaran Virtual Account (VA). Virtual Account (VA) tersebut nantinya diharapkan menjadi jalan keluar yang baik dalam hal metode pembayaran yang akan digunakan oleh mahasiswa. Virtual Account adalah nomor unik yang mewakili suatu rekening melalui kombinas nomor BIN dan nomor ID nasabah yang dapat digunakan oleh nasabah untuk membayar tagihan melalui jaringan bank Permata (Cabang, EDC, ATM, Mobile Banking) dan jaringan bank lain (cabang dan ATM) $)^{([\text {Ardhiansyah 2011]) }}$.

Permasalahan dalam metode pembayaran biaya perkuliahan adalah mahasiswa selalu sulit untuk mengingat nomor rekening pada Perguruan Tinggi Raharja. Jika mahasiswa tidak menyimpan nomor rekening pada Perguruan Tinggi Raharja mahasiswa harus meminta nomor rekening terlebih dahulu ke bagian keuangan sehingga menyulitkan mahasiswa jika ingin melakukan pembayaran perkuliahan. Mahasiswa setelah melakukan pembayaran di bank maka harus kembali ke kampus untuk menyerahkan bukti setoran atau transfer ke bagian keuangan. Layanan keuangan mahasiswa melihat transaksi dari tanggal validasi bank. Karena sistem pembayaran yang digunakan kurang efektif untuk mahasiswa maka digunakan sistem pembayaran Virtual Account. Penyediaan Virtual Account diharapkan bisa memberikan kemudahan bagi setiap mahasiswa Perguruan Tinggi Raharja dalam melakukan pembayaran biaya perkuliahan. 
Mengenai alokasi dana pendidikan dari APBN, Pasal 89 UU No. 12 Tahun 2012 tentang Pendidikan Tinggi ("UU Pendidikan Tinggi”) menyebutkan:

a. Perguruan Tinggi Negeri, dialokasikan untuk biaya operasional, dosen dan tenaga kependidikan, serta investasi dan pengembangan.

b. Perguruan Tinggi Swasta, dialokasikan sebagai bantuan tunjangan profesi dosen, tunjangan kehormatan profesor, serta investasi dan pengembangan.

c. Mahasiswa, sebagai dukungan biaya untuk mengikuti pendidikan tinggi.

\section{PERMASALAHAN}

Prosedur sistem yang sedang berjalan saat ini pada proses pembayaran biaya perkuliahan mahasiswa yang terdapat pada Perguruan Tinggi Raharja masih berjalan secara manual atau semi komputerisasi, yaitu seperti pencatatan atau pengecekan mahasiswa yang belum membayar masih menggunakan excel serta mahasiswa masih harus menyerahkan bukti pembayaran ke bagian keuangan (kasir). Ketika memberikan bukti pembayaran ke loket kasir masih membutuhkan waktu yang lama karena mahasiswa harus mengantri.

Sistem yang berjalan pembayaran dapat dilakukan diloket kasir dengan menggunakan kartu kredit (VISA/Mastercard) dan kartu debit mandiri serta debit BCA, pembayaran uang kuliah juga dapat dilakukan melalui Bank Mandiri KCP Ahmad Yani dan BCA KCU Serang atas nama Yayasan Nirwana Nusantara. Bukti setoran atau bukti transfer asli beserta fotokopinya sebanyak 2 (dua) lembar harus diserahkan kepada Layanan Keuangan mahasiswa untuk ditukarkan dengan kwitansi Perguruan Tinggi Raharja, jika tidak maka mahasiswa/i dianggap belum melakukan pembayaran yang dapat mengakibatkan mahasiswa/i tidak dapat memperoleh kartu ujian semester.



Sumber : Alur pembayaran perkuliahan (2013 : raharja.ac.id)

\section{Gambar 1. Alur Pembayaran Perkuliahan pada Perguruan Tinggi Raharja}

Tidak efektifnya pelayanan tersebut merugikan mahasiswa karena mahasiswa harus menukarkan bukti setor bank dengan kwintansi pembayaran kepada bagian keuangan (kasir) dan tidak akuratnya data serta lambatnya informasi yang disampaikan. Selain itu dua nomor rekening yang berbeda untuk digunakan dalam melakukan pembayaran membuat mahasiswa kesulitan mengingatnya. 
Rumusan masalah dalam penelitian ini adalah bagaimana pengembangan sistem pembayaran dengan online pada Perguruan Tinggi Raharja dengan menggunakan metode pembayaran virtual account.

Berdasarkan rumusan masalah yang telah di identifikasi maka tujuan yang ingin dihasilkan adalah menciptakan sistem yang dapat mengelola data keuangan, menciptakan sebuah sistem yang mampu mengontrol status keuangan mahasiswa, menciptakan suatu sistem yang mampu membantu Perguruan Tinggi Raharja dalam mengelola laporan keuangan.

\section{LITERATURE REVIEW}

Literature review adalah bahan yang tertulis berupa buku, jurnal yang membahas tentang topik yang hendak diteliti ([Menurut Hermawan 2009:45]). Banyak penelitian yang sebelumnya dilakukan mengenai virtual account. Dalam upaya pembuatan virtual account ini perlu dilakukan studi pustaka sebagai salah satu dari penerapan metode penelitian yang akan dilakukan.Berikut ini adalah 6 penelitian yang telah dilakukan dan memiliki kolerasi yang searah dengan penelitian yang akan dibahas dalam Jurnal ini diantaranya :

1. Penelitian yang dilakukan oleh Asep Saefullah, Nur Azizah, Andri Ansyah pada tahun 2015 penelitian ini berjudul "Perancangan Sistem Informasi Monitoring Antrian Pembayaran Kuliah Pada LKM Perguruan Tinggi Raharja". Pada penelitian ini perancangan penelitian dimulai dari proses pengumpulan data, analisis terhadap permasalahan, perancangan program menggunakan bahasa PHP (Hypertext Preprocessor), database MySQL dengan metode penelitian prototype. Hasil dari penelitian ini berupa sebuah sistem monitoring antrian yang dapat memonitoring pergerakan jumlah mahasiswa sehingga pada saat mengantri tidak perlu lagi berdiri di depan LKM, mahasiswa dapat melakukan aktivitas yang lain dan hanya sesekali melihat pada tampilan nomor jumlah mahasiswa antri.

2. Penelitian yang dilakukan oleh J.Rolles Herwin Sihombing, Selvyna Theresia pada tahun 2015 penelitian ini berjudul "Perancangan Sistem Informasi Prepaid di Perusahaan Makanan Siap Saji XYZ". Dengan mengimplementasikan Prepaid baik di offline maupun online, menjadikan XYZ perusahaan makanan siap saji dengan pengembangan teknologi paling terdepan di Indonesia, setidaknya sampai saat ini. Hasil dari implementasi ini akan meningkatkan dan mempermudah transaksi Home Delivery (HD) dan Online Tunes (OT), serta kombinasi dengan sistem point loyalty akan memberikan keuntungan lain bagi customer, yakni mendapatkan item tertentu secara gratis melalui redemption point yang terkumpul. CRM yang dibangun akan mempermudah analisa transaksi selain profiling customer XYZ. Transaksi pembayaran yang akan didukung adalah transaksi pembayaran dengan menggunakan Virtual Account (VA).

3. Penelitian yang dilakukan oleh Nurhayati, Hendra Bayu Suseno, Andi Malik Rizki Maulana pada tahun 2014 penelitian ini berjudul "Pengembangan Web Service Online Pembayaran Online Menggunakan Simple Object Access Protocol (SOAP) di Sekolah Dasar Islam AlAzhar BSD". Prosedur pembayaran online dimulai dari pembayaran yang menyetor sejumlah uang ke virtual account kemudian sistem bank akan mengirimkan data setoran tersebut sebagai data pembayaran ke web service Al-Azhar BSD. Web service Al-Azhar BSD akan memperoleh data pembayaran dan menyimpannya di database jika pembayaran valid atau menolak pembayaran jika tidak valid. Web Service mengambil data tagihan berdasarkan 
nomor virtual account yang dikirimkan sistem bank. Data yang diperoleh dikirimkan ke sistem bank.

4. Penelitian yang dilakukan oleh Vincent Fabrian Wibowo pada tahun 2014 penelitian ini berjudul "Determinan Penggunaan Virtual Account dengan Pendekatan Integrasi Model TPB dan TAM di Universitas Katolik Soegijapranata Semarang". Penelitian ini bertujuan untuk mencari bukti empiris bahwa perilaku nyata penggunaan Virtual Account didasari/dipengaruhi oleh model integrasi TPB (Norma Sosial, Norma Subjektif, dan Persepsi Pengendali Perilaku) dan TAM (Persepsi Kegunaan, Persepsi Kemudahan Penggunaan, Sikap, dan Minat). Objek dalam penelitian ini adalah mahasiswa Universitas Katolik Soegijapranata Semarang yang menggunakan Virtual Account milik Bank Internasional Indonesia yang memiliki nomor rekening baik di Bank Internasional Indonesia. Pengujian dilakukan dengan SPSS 16.0 dan SEM (Struktural Equation Model) dengan program AMOS 18.0 .

5. Penelitian yang dilakukan oleh Alfa Maulana pada tahun 2012 penelitian ini berjudul "Peran Virtual Account Dalam Meningkatkan Produktivitas Sekolah Melalui Rekonsiliasi Uang Sekolah". Dengan menerapkan sistem Virtual Account di beberapa sekolah yang menjadi target market, maka Bank Danamon disamping dapat membantu manajemen sekolah meningkatkan produktivitasnya juga sekaligus dapat memperluas pangsa pasarnya di dalam persaingan bisnis perbankan. Penulis ingin mengetahui peran dari sistem Virtual Account itu sendiri dalam membantu pihak manajemen sekolah meningkatkan produktivitasnya melalui rekonsiliasi pembayaran uang sekolah. Dimana dengan menerapkan sistem tersebut maka pembuatan rekonsiliasi tersebut akan terintegrasi baik menjadi sebuah proses yang lebih cepat dalam hal penyajian dan meminimalisir faktor human-error.

6. Penelitian Kerry Dennis Brown pada tahun 2009 penellitian ini berjudul "Payment card with internally generated virtual account numbers for its magnetic stripe encoder and user display". A payment card consists of a virtual account number internal generation and screen users for online transactions. Offline transaction with a merchant card reader is activated by a magnet array positioned behind the magnetic strip on the back of the card. Internal virtual account number generator capable of programming the magnetic bits are encoded in the magnetic strip to reflect the latest virtual account number. Internal virtual account number generator generates a sequence of virtual numbers that can be predicted and approved by penerbit.Penemuan bank is related to a payment card, and more particularly to a payment card with an internal virtual personal account number which can be viewed by the user so as to allow internet purchases, and that has internal writeable magnetic data stripe that can be read by the machine by the point-of-sale card readers heritage. Limitations with Virtual Account Number is the internet, or at least require the use of a personal computer to get every new number, and the transaction must be online.

7. Penelitian Albert Talker pada tahun tahun 2007 penelitian ini berjudul "Multi-account security verification system with a virtual account and linked multiple real accounts". A multi account security verification system, which consists off a virtual account card and a central authentication enterprise. The cardholder is able to select one of the real accounts belonging to the account owner by adding control digits to the virtual account number. The real account is retrieved from the Central Authentication Enterprise by accessing the virtual account number record stored in a system database thereby retrieving the selected real 
account number associated with the control digits and the virtual account number. The database may also store a plurality of secret keys or public/private key sets associated with the virtual account number in addition to optional BIO information, which can be used for authentication and authorization.

Setelah melakukan tinjauan dari enam literature review yang ada, telah banyak penelitian mengenai pembayaran menggunkan virtual account untuk meningkatkan metode pembayaran. Karena Perguruan Tinggi Raharja media pembayaran yang diterapkan masih sacara manual oleh karena itu penulis melakukan penelitian tentang virtual account untuk meningkatkan fasilitas kampus pada bagian keuangan. Oleh karena itu penulis membahas hal "Rancangan Virtual Account Sebagai Media Pembayaran pada Perguruan Tinggi Raharja" agar dapat meningkatkan metode pembayaran sebelumnya agar lebih memudahkan mahasiswa dalam melakukan transaksi pembayaran perkuliahan.

\section{PEMECAHAN MASALAH}

Untuk mengatasi berbagai masalah tersebut, maka diperlukan sebuah sistem yang efektif dan efisien dalam melakukan pembayaran.Dari rumusan masalah tersebut menghasilkan 2 pemecahan masalah yaitu dengan adanya Virtual Account maka diharapkan sistem pembayaran yang dilakukan secara online dengan menggunakan nomor rekening yang unik yaitu 5 digit kode bank dan 10 digit NIM mahasiswa sehingga memudahkan identifikasi pembayaran yang masuk, mahasiswa tidak perlu menukarkan slip setoran bank ke kasir dan mengantri karena bukti pembayaran dapat dikirimkan melalui Rinfo lkm@raharja.info. Mahasiswa juga tidak perlu membuka rekening baru untuk dapat menggunakan fasilitas Virtual Account dan bebas biaya untuk transaksi transfer yang dilakukan antar rekening, bahkan bagi mahasiswa yang tidak memiliki rekening pun dapat melakukan melalui transaksi kiriman uang berupa LLG maupun RTGS ataupun warkat dari bank lain. Pada pemecahan masalah menggunakan mind mapping dan analisa SWOT:

\section{Mind Mapping}

Mind mapping adalah cara mengembangkan kegiatan berpikir ke segala arah, menangkap berbagai pikiran dalam berbagai sudut. Mind mapping mengembangkan cara berpikir divergen dan berpikir kreatif. Mind mapping yang sering kita sebut dengan peta konsep adalah alat berpikir organisasional yang sangat hebat yang juga merupakan cara termudah untuk menempatkan informasi ke dalam otak dan mengambil informasi itu ketika dibutuhkan ([Tony Buzan , 2008:4])

Ditinjau dari segi waktu mind mapping juga dapat mengefisienkan penggunaan waktu dalam mempelajari suatu informasi. Hal ini utamanya disebabkan karena metode ini dapat menyajikan gambaran menyeluruh atas suatu hal, dalam waktu yang lebih singkat. Dengan kata lain, Mind mapping mampu memangkas waktu belajar dengan mengubah pola pencatatan linear yang memakan waktu menjadi pencatatan yang efektif yang sekaligus langsung dapat dipahami oleh individu.

Vol.2 No.2 - Agustus 2016 
Pada metode Mind Mapping ini menghasilkan sebagai berikut yaitu penjelasan virtual account merupakan nomor unik yang mewakili suatu rekening, untuk nomor virtual account pada Perguruan Tinggi Raharja yaitu terdiri dari 5 digit kode yayasan dan 10 digit NIM mahasiswa. Tujuan $V A$ untuk mewujudkan sistem pembayaran secara online, untuk mengetahui pengaruh $V A$ terhadap tingkat kualitas pelayanan bagian keuangan, dan untuk mengetahui pengaruh $V A$ terhadap ketetapan dan keakuratan dalam memberikan informasi. Kekurangan VA yaitu masih adanya mahasiswa dan orang tua yang belum mengetahui $V A$. Kelebihan VA yaitu memudahkan mahasiswa dalam menghafal nomor rekening, mahasiswa tidak perlu mengantri dikasir setelah melakukan pembayaran, dan transaksi menjadi lebih mudah, cepat, akurat, dan efisien. User pada $V A$ yaitu kepala keuangan, pimpinan, kasir, dan mahasiswa. Lima point mind mapping tersebut diambil berdasarkan fakta yang sesungguhnya yang terjadi pada Perguruan Tinggi Raharja hasil dari penelitian yang dilakukan oleh peneliti.
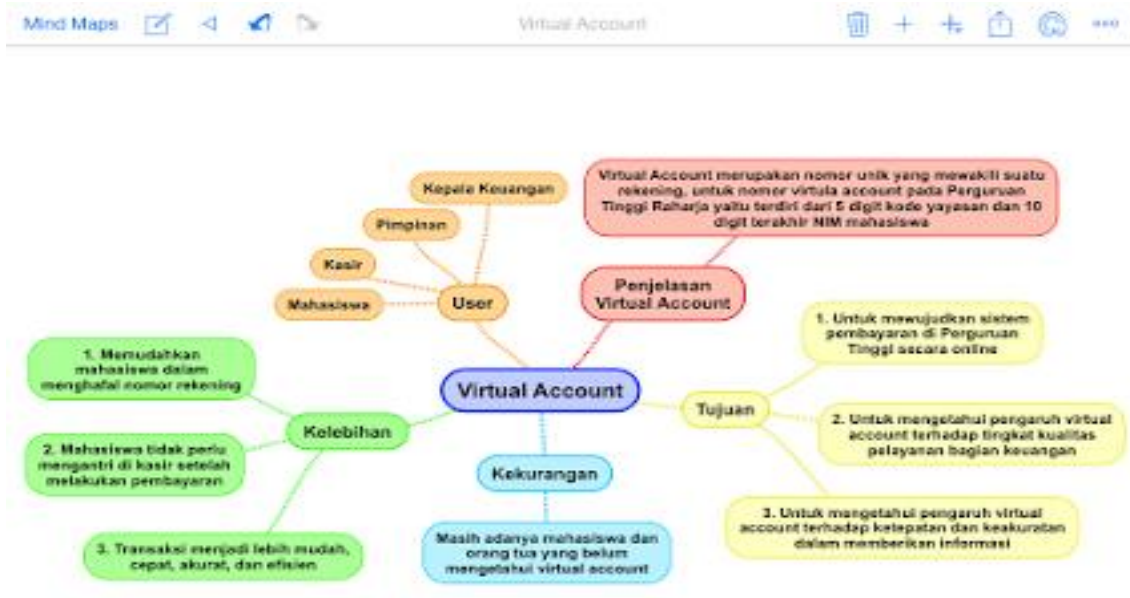

Gambar 2. Mindmap virtual account

\section{SWOT}

SWOT digunakan untuk menilai kekuatan-kekuatan dan kelemahan-kelemahan dari sumbersumber daya yang dimiliki perusahaan dan kesempatan-kesempatan eksternal dan tantangantantangan yang dihadapi ([Jogiyanto 2005]).

Pada pemecahan masalah menggunakan metode SWOT yang kemudian akan diaplikasikan untuk menemukan pembayaran online pada Perguruan Tinggi Raharja. Langkah - langkah tersebut dapat dijelaskan pada sebagai berikut : 


\section{Tabel 1. Analisa SWOT}

\begin{tabular}{|c|c|c|}
\hline Faktor Internal & $\begin{array}{l}\text { Strenght } \\
\text { (Kekuatan) }\end{array}$ & $\begin{array}{l}\text { Weakness } \\
\text { (Kelemahan) }\end{array}$ \\
\hline Faktor Eksternal & 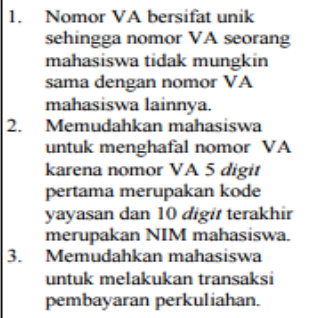 & $\begin{array}{l}\text { 1. Masih terdapat } \\
\text { mahasiswa yang } \\
\text { tidak tahu } \\
\text { tentang Virtual } \\
\text { Account. }\end{array}$ \\
\hline Opportunity(Peluang) & Strategy SO & Strategy wo \\
\hline $\begin{array}{l}\text { 1. Pembayaran online kini } \\
\text { semakin canggih. } \\
\text { 2. Dibutuhkannya akses } \\
\text { pembayaran yang bersifat } \\
\text { online dan real time. }\end{array}$ & 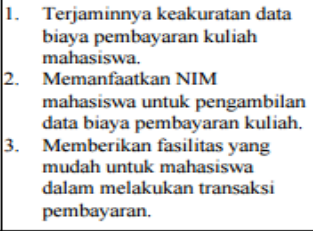 & $\begin{array}{ll}\text { 1. } & \text { Melakukan } \\
\text { sosialisasi } \\
\text { tentang Virtual } \\
\text { Accoumt kepada } \\
\text { mahasiswa. }\end{array}$ \\
\hline Threat (Ancaman) & Strategy ST & Strategy WT \\
\hline $\begin{array}{l}\text { 1. Mahasiswa tidak mengerti } \\
\text { melakukan transaksi } \\
\text { pembayaran menggunakan } \\
\text { Virtual Account. } \\
\text { 2. Tidak dapat melakukan } \\
\text { transaksi pembayaran jika } \\
\text { bank sedang mengalami } \\
\text { gangguan (offline). }\end{array}$ & $\begin{array}{l}\text { 1. Memberikan panduan kepada } \\
\text { mahasiswa tentang cara } \\
\text { transaksi pembayaran } \\
\text { menggunakan Virtual } \\
\text { Accoumt. }\end{array}$ & $\begin{array}{l}\text { 1. } \begin{array}{l}\text { Memberikan } \\
\text { betasan waktu } \\
\text { pembayaran. }\end{array} \\
\text {. }\end{array}$ \\
\hline
\end{tabular}

Setelah membandingkan antara faktor eksternal peluang dan ancaman dengan faktor internal kekuatan dan kelemahan sehingga dari analisis tersebut dapat diambil suatu keputusan strategis suatu organisasi, yaitu sebagai berikut, Strategi SO diterapkan berdasarkan perbandingan antara strength (kekuatan) dan opportunity (peluang), yaitu dengan memanfaatkan kekuatan perusahaan untuk memaksimalkan peluang yang dipunya oleh perusahaan. Strategi yang didapatkan adalah Terjaminnya keakuratan data biaya pembayaran kuliah mahasiswa, memanfaatkan NIM mahasiswa untuk pengambilan data biaya pembayaran kuliah, dan memberikan fasilitas yang mudah untuk mahasiswa dalam melakukan transaksi pembayaran. Strategi ST diterapkan berdasarkan perbandingan antara strength (kekuatan) dan thread (ancaman), yaitu dengan memanfaatkan strategi kekuatan yang dipunyai oleh perusahaan untuk dapat meminimalisir ancaman yang ada bagi perusahaan. Strategi yang didapatkan adalah memberikan panduan kepada mahasiswa tentang cara transaksi pembayaran menggunakan Virtual Account. Strategi WO diterapkan berdasarkan perbandingan antara weakness (kelemahan) dan opportunity (peluang), yaitu dengan meminimalisirkan kelemahan yang dimiliki oleh perusahaan untuk dapat memaksimalkan banyak peluang yang bisa didapat oleh perusahaan. Strategi yang didapatkan adalah melakukan sosialisasi tentang Virtual Account kepada mahasiswa. Strategi WT diterapkan berdasarkan perbandingan antara weakness (kelemahan) dan thread (ancaman), yaitu dengan mengetahui kelemahan yang dipunyai oleh perusahaan untuk dapat segera meminimalisir ancaman yang akan mengancam perusahaan jika kelemahan tidak segera diatasi. Strategi yang didapatkan adalah memberikan batasan waktu pembayaran. 


\section{Flowchart Rancangan Aplikasi}

Flowchart adalah penggambaran secara grafik dari langkah-langkah dan urut-urutan prosedur dari suatu program ([Menurut Adelia 2011:116]). Flowchart program dalam pemecahan masalah merupakan keterangan yang lebih rinci tentang bagaimana setiap langkah program atau prosedur sesungguhnya akan dilaksakan. Flowchart ini menunjukan setiap langkah program atau prosedur dalam urutan yang tepat saat terjadi. Berikut flowchart pembayaran Virtual Account menggunakan ATM pada Perguruan Tinggi Raharja sebagai berikut :

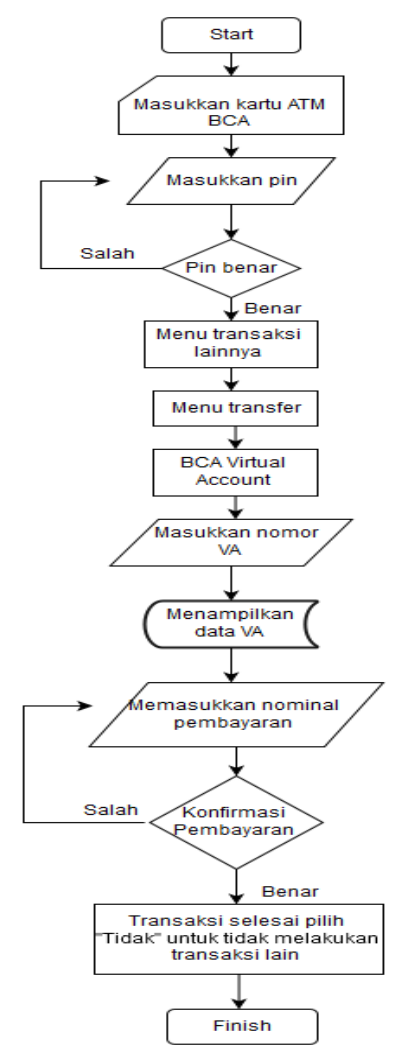

\section{Gambar 3. Flowchart Sistem Pembayaran Virtual Account BCA Via ATM}

Dari gambar di atas dapat dijabarkan bahwa hal yang pertama dilakukan oleh mahasiswa adalah memasukan kartu ATM BCA dan masukan PIN setelah pin benar maka dapat meneruskan ke menu pembayaran lain jika tidak berhasil maka kembali memasukan kartu ATM dan PIN. Dari menu pembayaran pilih menu transfer lalu pilih menu BCA virtual account, setelah itu masukan nomor virtual account yang didapat dari kampus dan akan muncul nama, nim serta jumlah yang akan dibayar. Masukan nominal pembayarannya dan pastikan konfirmasi pembayarannya sudah benar setelah selesai kartu ATM akan keluar. Jika salah memasukan nominal pembayarannya maka ulang kembali input nominal dan pastikan pembayaran nya sudah benar. 


\section{Listing Program}

Pada virtual account ini menggunakan aplikasi GO dengan menggunakan bahasa program CSS. Berikut merupakan kodingannya :

\begin{tabular}{|c|c|}
\hline 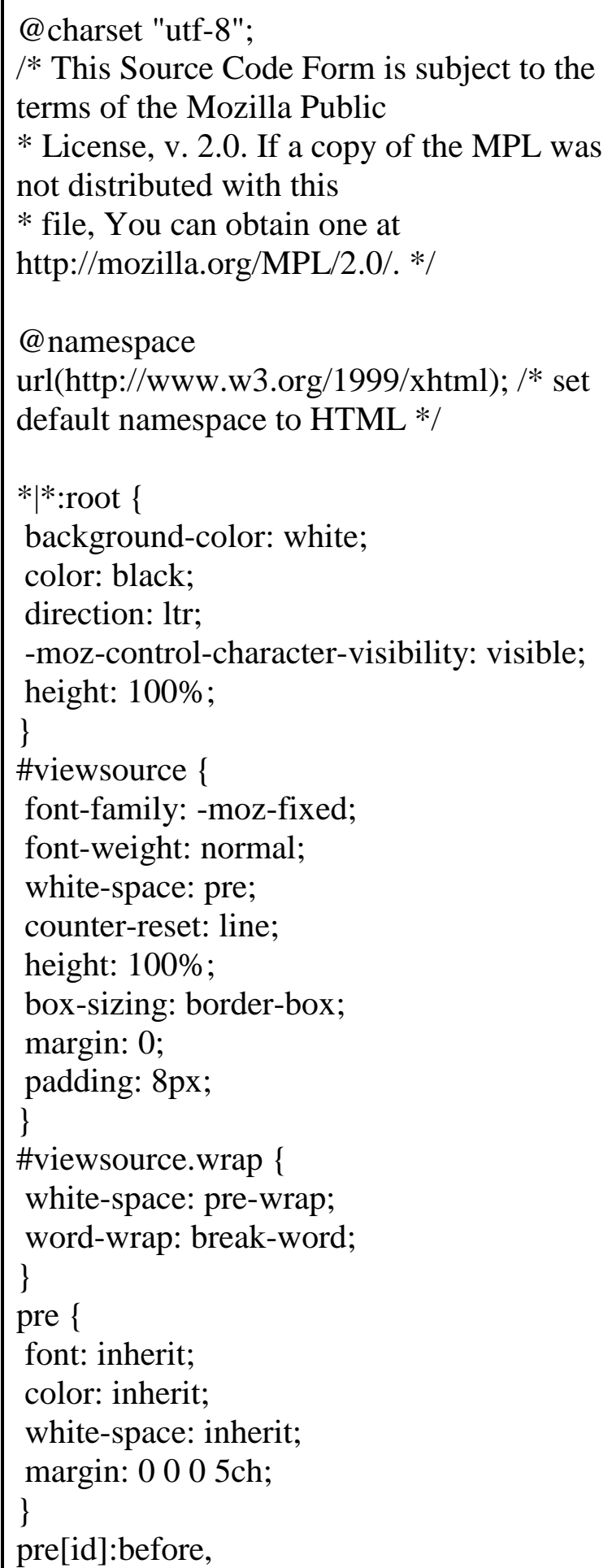 & $\begin{array}{l}\text {.highlight .start-tag \{ } \\
\text { color: purple; } \\
\text { font-weight: bold; } \\
\text { \} } \\
\text {.highlight .end-tag \{ } \\
\text { color: purple; } \\
\text { font-weight: bold; } \\
\text { \} } \\
\text {.highlight .comment \{ } \\
\text { color: green; } \\
\text { font-style: italic; } \\
\} \\
\text {.highlight .cdata \{ } \\
\text { color: \#CC0066; } \\
\} \\
\text {.highlight .doctype \{ } \\
\text { color: steelblue; } \\
\text { font-style: italic; } \\
\} \\
\text {.highlight .pi \{ } \\
\text { color: orchid; } \\
\text { font-style: italic; } \\
\} \\
\text {.highlight .entity \{ } \\
\text { color: \#FF4500; } \\
\text { font-weight: normal; } \\
\} \\
\text {.highlight .text \{ } \\
\text { font-weight: normal; } \\
\text { \} } \\
\text {.highlight .attribute-name \{ } \\
\text { color: black; } \\
\text { font-weight: bold; } \\
\} \\
\text {.highlight .attribute-value \{ } \\
\text { color: blue; } \\
\text { font-weight: normal; } \\
\text {.highlight .markupdeclaration \{ }\end{array}$ \\
\hline
\end{tabular}

Vol.2 No.2 - Agustus 2016 


\begin{tabular}{|l|l|}
\hline span[id]:before \{ & color: steelblue; \\
content: counter(line) " "; & font-style: italic; \\
counter-increment: line; & \} \\
-moz-user-select: none; & span:not(.error), a:not(.error) \{ \\
display: inline-block; & unicode-bidi: embed; \\
width: 5ch; & \} \\
margin: 000 -5ch; & span[id] \{ \\
text-align: right; & unicode-bidi: -moz-isolate; \\
color: \#ccc; & \} \\
font-weight: normal; & .highlight .error, \\
font-style: normal; & .highlight .error > :-moz-any(.start-tag, .end- \\
\} & tag, .comment, .cdata, .doctype, \\
& .attribute-value) \{ \\
& color: red; \\
& font-weight: bold; $;$ \\
& \} \\
& \\
\hline
\end{tabular}

\section{PROTOTYPE}

Proses pengembangan sistem seringkali menggunakan pendekatan prototipe (prototyping). Metode ini sangat baik digunakan untuk menyelesesaikan masalah kesalahpahaman antara user dan analis yang timbul akibat user tidak mampu mendefinisikan secara jelas kebutuhannya ([Mulyanto 2009]). Prototype adalah proses pembuatan model sederhana software yang mengijinkan pengguna memiliki gambaran dasar tentang program serta melakukan pengujian awal. Prototype memberikan fasilitas bagi pengembang dan pemakai untuk saling berinteraksi selama proses pembuatan, sehingga pengembang dapat dengan mudah memodelkan perangkat lunak yang akan di buat. Pada prototype $V A$ ini merupakan gambaran saat melakukan transaksi pembayaran VA via transfer ATM BCA Non Tunai :

\section{Masukkan kartu ATM anda, kemudian masukkan nomor PIN anda}

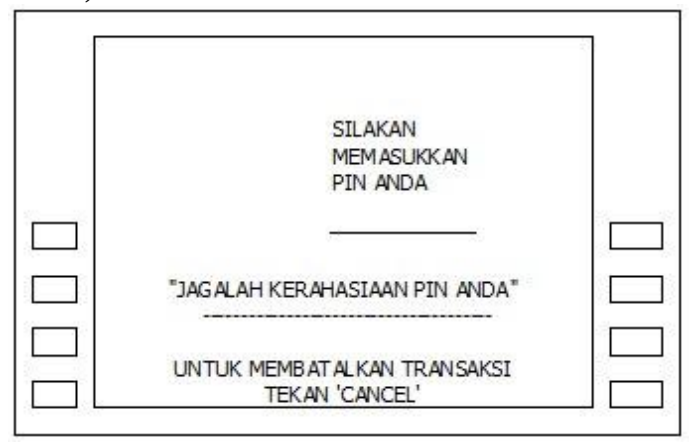

Prototype 1. Tampilan awal mesin ATM pada mesin ATM 


\section{Pilih menu TRANSFER}

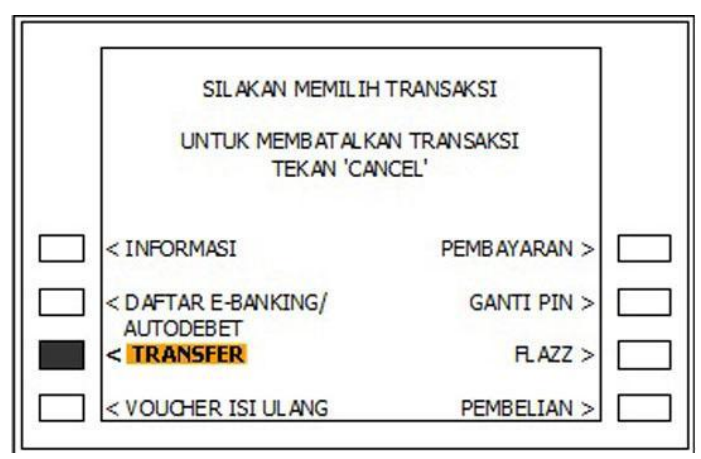

Prototype 2. Tampilan menu transaksi pada mesin ATM

\section{Pilih menu KE REK BCA VIRTUAL ACCOUNT}

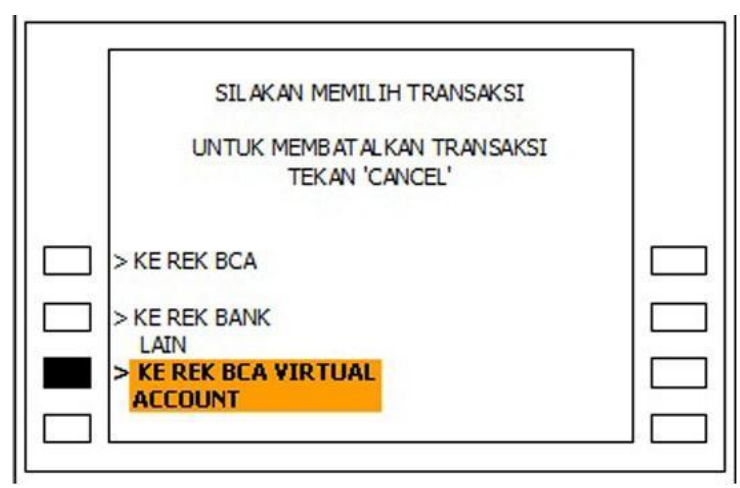

Prototype 3. Tampilan menu memilih transaksi pada mesin ATM

4. Masukkan nomor Virtual Account anda, pilih BENAR

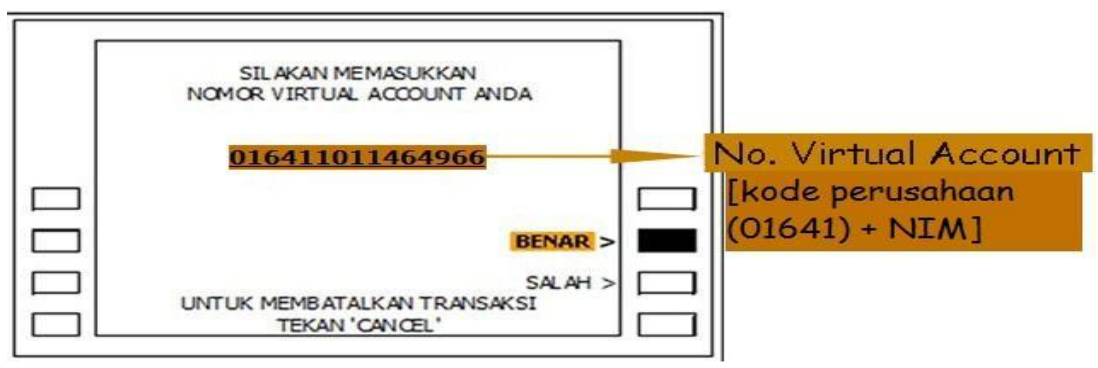

Prototype 4. Tampilan memasukkan nomor virtual account pada mesin ATM 
5. Anda bisa memasukkan berita (optional, maksimum 32 digit alphanumeric). Jika sudah pilih "BENAR"

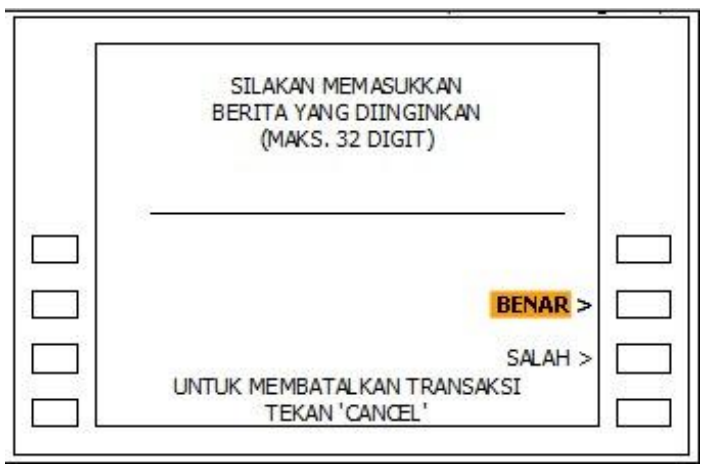

Prototype 5. Tampilan memasukkan berita pada mesin ATM

\section{Tampilan selanjutnya}

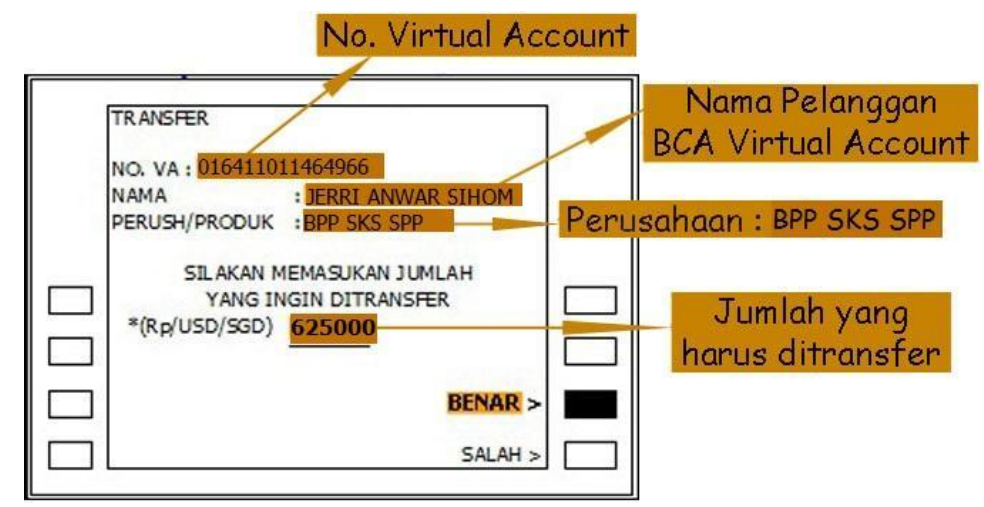

Prototype 6. Tampilan data pada mesin ATM

\section{IMPLEMENTASI}

Virtual Account telah di implementasikan pada Perguruan Tinggi Raharja sebagai sarana pembayaran yang aman, efektif dan efisien.

A. Tampilan Pengiriman Email Rinfo

Bagian Keuangan mengirimkan email ke seluruh mahasiswa perihal no virtual account. Nomor Virtual Account berisikan 15 digit dimana 5 digit pertama merupakan kode yayasan dan 10 digit terakhir merupakan nim mahasiswa. 


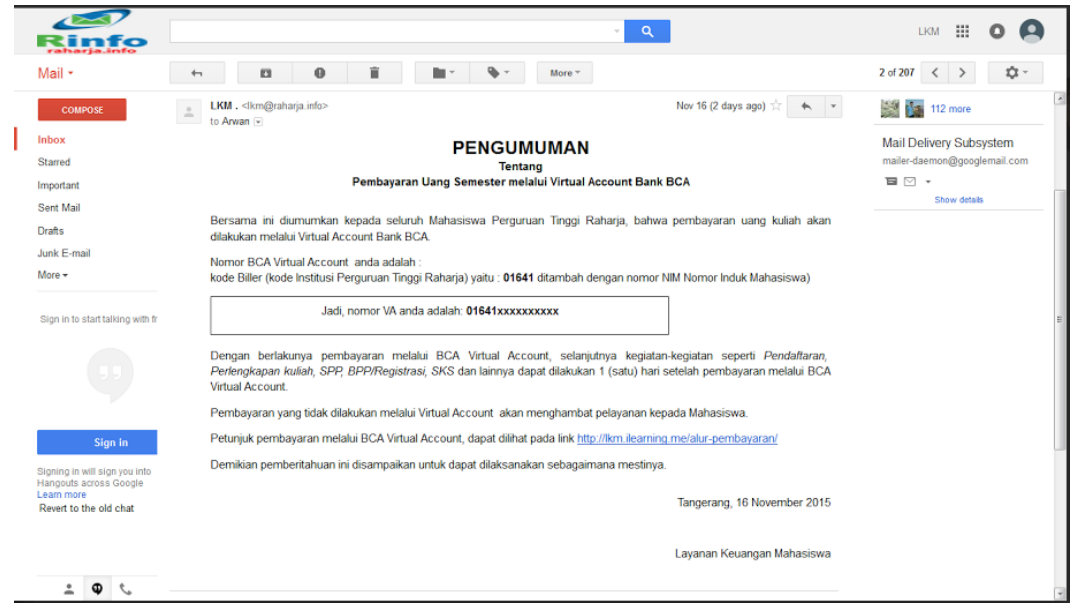

Gambar 4. Pengumuman VA via Rinfo

B. Tampilan menu tagihan dilayar Virtual Account

Layar ini menampilkan nama, nomor Virtual Account serta jumlah yang akan dibayar serta konfirmasi apakah ingin membayar atau tidak. Jika ingin membayar bisa klik YA jika tidak ingin membayar bisa klik TIDAK.

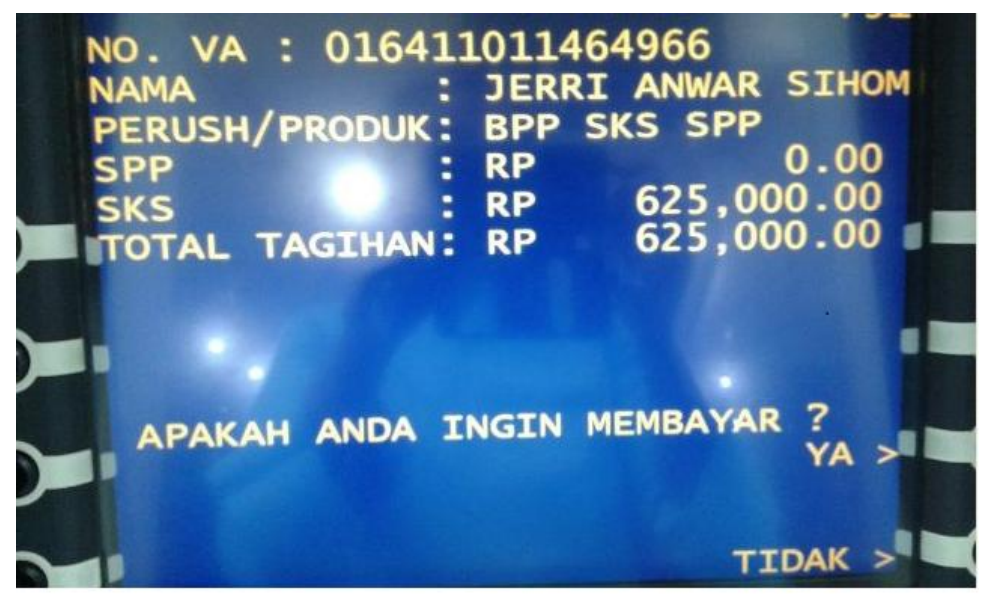

Gambar 5. Tampilan VA pada menu ATM

C. Tampilan alur pembayaran

Alur pembayaran bisa dilihat pada portal http://www.lkm.ilearning.me/alur-pembayaran/ disitu akan kelihatan alur pembayaran menggunakan ATM BCA dan selain BCA, serta pembayaran melalui setor tunai di teller. 


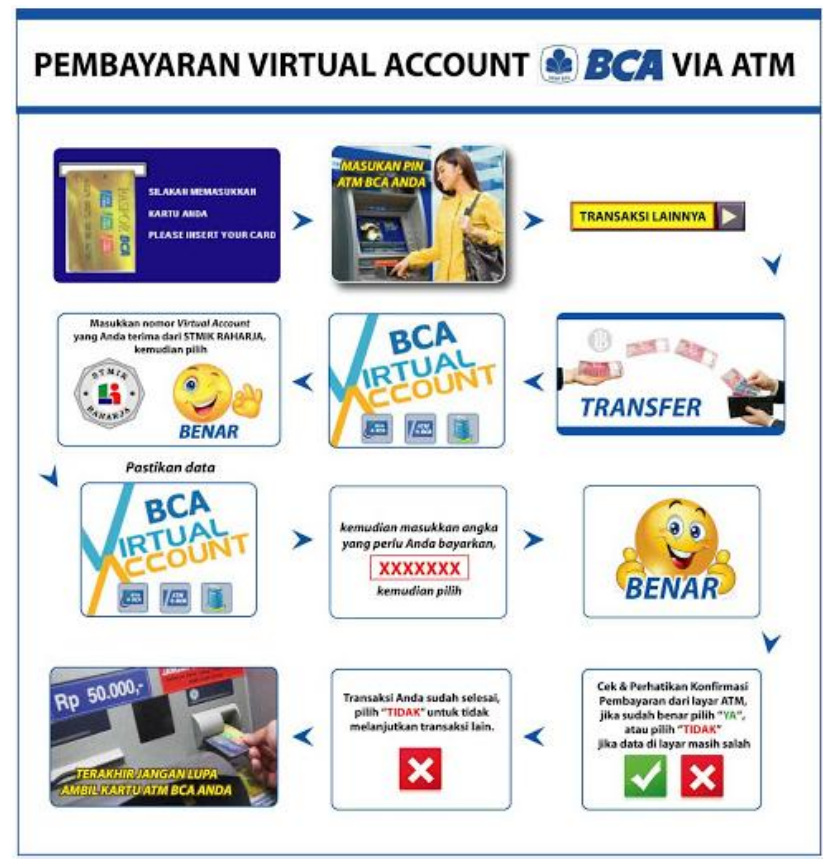

\section{Gambar 6. Alur Virtual Account via ATM BCA}

D. Berikut merupakan alur registrasi pembayaran hingga mendapatkan email

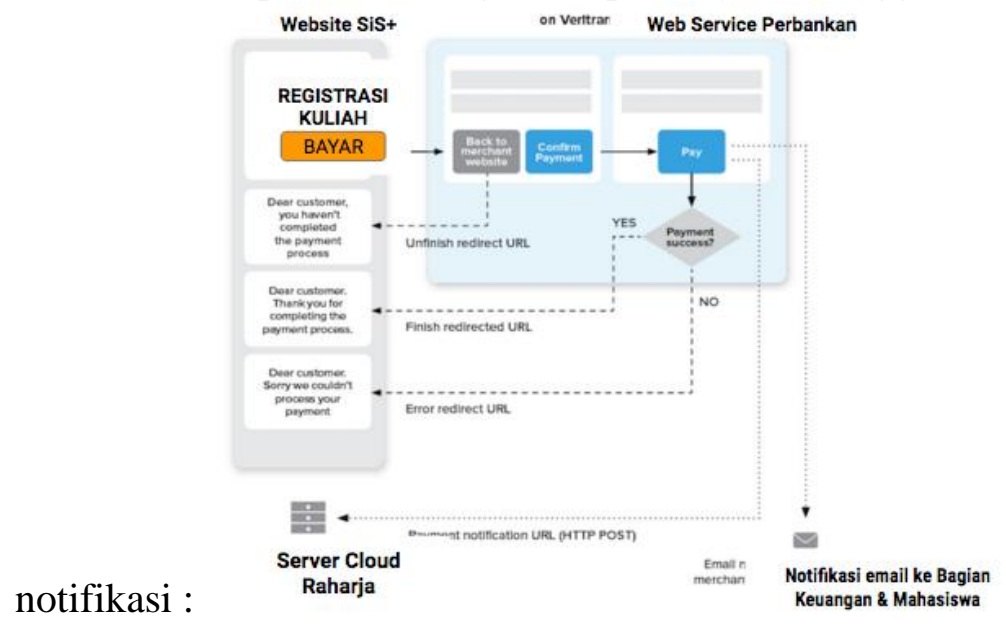

Gambar 7. Alur Registrasi

\section{KELEBIHAN VIRTUAL ACCOUNT}

Memudahkan mahasiswa dalam menghafal nomor rekening karena nomor rekening terdiri dari 5 digit kode yayasan dan 10 digit NIM mahasiswa dan pembayaran telah dilakukan secara online. Mahasiswa tidak perlu datang ke kampus untuk melakukan transaksi pembayaran dan mengantri di loket kasir serta tidak perlunya membuka nomor rekening untuk mendapatkan fasilitas Virtual Account. Identifikasi transaksi menjadi lebih mudah, cepat dan akurat serta efisiensi kampus pun akan meningkat karena biaya telepon, arsip dan pekerjaan dapat di minimalisir. Adanya 
notifikasi realtime yang memungkinkan pimpinan dapat mengetahui informasi saat itu juga, tepat sesaat setelah mahasiswa melakukan transaksi.

\section{KELEMAHAN VIRTUAL ACCOUNT}

Masih adanya mahasiswa dan orang tua yang belum mengetahui virtual account dan hanya menganggap virtual account sebagai nomor biasa sehingga dia kesulitan dalam transaksi di atm karena harus memasukki beberapa menu sehingga manfaat maksimal dari virtual account tidak dapat dinikmati.

\section{KESIMPULAN}

Dengan demikian dapat disimpulkan, penelitian ini menggunakan metode mind mapping dan analisa SWOT. Menggunakan sistem pembayaran secara online lebih efisien, aman, nyaman dan cepat dibandingkan dengan pembayaran secara manual yang diterapkan pada Perguruan Tinggi Raharja sebelumnya. Pengembangan sitem pembayaran pembayaran menggunakan virtual account memudahkan mahasiswa dalam melakukan pembayaran. Sistem pembayaran virtual account ini sangat efisien untuk mahasiswa karena mudahnya menghafal nomor virtual account jika ingin melakukan transaksi pembayaran perkuliahan dan juga aman untuk mahasiswa. Dengan menggunakan virtual pembayaran perkuliahan menjadi lebih aman, efektif karena mahasiswa tidak perlu mengantri ke bagian kasir setelah melakukan transfer pembayaran perkuliahan, dan dengan menggunakan virtual account data jumlah pembayaran setiap mahasiswa akan ditampilkan ketika sedang melakukan transfer pembayaran jadi tidak menimbulkan pembayaran yang kurang maupun lebih ketika sedang melakukan transfer pembayaran. Dengan adanya sistem pembayaran online pada Perguruan Tinggi Raharja diharapkan dapat memberikan kemudahan mahasiswa dalam melakukan pembayaran biaya kuliah dan informasi keuangan yang disajikan akurat, cepat serta efisien sesuai kebutuhan yang telah dianalisa dengan menggunakan metode SWOT yang dapat meningkatkan mutu Perguruan Tinggi Raharja.

\section{DAFTAR PUSTAKA}

[1] Adelia. 2011. "Implementasi Customer Relationship Management (CRM) pada Sistem Reservasi Hotel berbasis Website dan Desktop". Bandung: Universitas Kristen Maranatha. Vol. 6, No. 2, September 2011:113-126.

[2] Ardhiansyah, A (2011). Virtual Account Sebagai Salah Satu Channel Pembayaran Asuransi Tafakul Keluarga. Blog Pribadi. Diakses pada 11 Mei 2011 dari https://putrasriwijaya.wordpress.com/2011/05/11/virtual-account/.

[3] Brown, Kerry Dennis (2009). "Payment card with internally generated virtual account numbers for its magnetic stripe encoder and user display". US7472829 B2. 6 Januari 2009

[4] Buzan, Tony. 2008. “Buku Pintar Mind Map”. Jakarta : PT. Gramedia Pustaka Utama.

\section{Vol.2 No.2 - Agustus 2016}


[5] Hasibuan (2001:117). "Buku Manajemen Sumber Daya Manusia”.

[6] Hermawan. 2009. “Penelitian Bisnis”. Jakarta: Grasindo.

[7] Kajian Pustaka.2012. Pengertian SWOT. "http://www.kajianpustaka.com/2013/03/strenghtsweakness-opportunities". 4 Febuari 2016.

[8] Maulana, Alfa (2012). "Peran Virtual Account Dalam Meningkatkan Produktivitas Sekolah Melalui Rekonsiliasi Uang Sekolah”. Yogjakarta: Universitas Gadjah Mada.

[9] Nurhayati, Hendra Bayu Suseno, Andi Malik Rizki Maulana. "Pengembangan Web Service Online Pembayaran Online Menggunakan Simple Object Access Protocol (SOAP) di Sekolah Dasar Islam Al-Azhar BSD”. Jurnal Pseudocode, Vol. 2.No. 1, September 2014

[10]Perguruan Tinggi Raharja.2013.Alur Pembayaran Perkuliahan. http://raharja.ac.id/acid/informasi/alurpembayaran. 26 Januari 2016.

[11]Saefullah, Asep. Azizah, Nur. Ansyah, Andri. "Perancangan Sistem Informasi Monitoring Antrian Pembayaran Kuliah Pada LKM Perguruan Tinggi Raharja". Creative Communication and Innovative Technology (CCIT), Vol. 9.No. 1, Juni 2015

[12]Sihombing, J.Rolles Herwin. Theresia,Selvyna (2015). "Perancangan Sistem Informasi Prepaid di Perusahaan Makanan Siap Saji XYZ. Computer, Mathematics and Engineering Applications (ComTech)", Vol 6. No. 2, Juni 2015

[13]Talker, Albert (2007). "Multi-account security verification system with a virtual account and linked multiple real accounts". US20070185820 A1. 9 Agustus 2007

[14]Wibowo, Vincent Fabrian (2014). "Determinan Penggunaan Virtual Account dengan Pendekatan Integrasi Model TPB dan TAM di Universitas Katolik Soegijapranata Semarang". Semarang: Universitas Katolik Soegijapranata. 